\title{
Transition Matrix Models of Consumer Credit Ratings
}

\begin{abstract}
Although the corporate credit risk literature has many studies modelling the change in the credit risk of corporate bonds over time, there is far less analysis of the credit risk for portfolios of consumer loans. However behavioural scores, which are commonly calculated on a monthly basis by most consumer lenders are the analogues of ratings in corporate credit risk. Motivated by studies in corporate credit risk, we develop a Markov chain model based on behavioural scores to establish the credit risk of portfolios of consumer loans. Although such models have been used by lenders to develop models for the Basel Accord, there is no published literature on them. The model we suggest differs in many respects from the corporate credit ones based on Markov chains - such as the need for a second order Markov chain, the inclusion of economic variables and the age of the loan. The model is applied using data on a credit card portfolio from a major UK bank.
\end{abstract} JEL classification: C25; G21; G33

Keywords: Markov chain; Credit risk; Logistic regression; Credit scoring

\section{Introduction}

Since the mid 1980s, banks' lending to consumers has exceeded that to companies ( Crouhy et al 2001). However it was only with the subprime mortgage crisis of 2007 and the subsequent credit crunch that it was realised what an impact such lending had on the banking sector and also how under researched it is compared with corporate lending models. In particular the need for robust models of the credit risk of portfolios of consumer loans has been brought into sharp focus by the failure of the ratings agencies 
to accurately assess the credit risks of Mortgage Backed Securities (MBS) and collateralized debt obligations (CDO) which are based on such portfolios. There are many reasons put forward for the subprime mortgage crisis and the subsequent credit crunch ( Hull 2009, Demyanyk and van Hemert 2008) but clearly one reason that the former led to the latter was the lack of an easily updatable model of the credit risk of portfolios of consumer loans. This lack of a suitable model of portfolio level consumer risk was first highlighted during the development of the Basel Accord, when a corporate credit risk model was used to calculate the regulatory capital for all types of loans ( Basel Committee on Banking Supervision 2005) even though the basic idea of such a model that default occurs when debts exceed assets - is not the reason why consumers default. This paper develops a model for the credit risk of portfolios of consumer loans based on behavioural scores for the individual consumers, whose loans make up that portfolio. Such a model is attractive to lenders, since almost all lenders calculate behavioural scores for all their borrowers on a monthly basis. The behavioural score is usually translated into the default probability over a fixed time horizon ( usually one year) in the future for that borrower, but one can consider it as a surrogate for the unobservable creditworthiness of the borrower. We build a Markov chain credit risk model based on behavioural scores for consumers which has similarities with the reduced form mark to market corporate credit risk models based on the rating agencies‘ grades, ( Jarrow, Lando, and Turnbull 1997). Such behavioural score based Markov chain models have been developed by lenders for their Basel modelling but no analysis has appeared in the literature and in this paper we discuss what features should be included in such models and compare a standard and a more sophisticated version of the model. The methodology constructs an empirical 
forecasting model to derive a multi-period distribution of the default rate for long time horizons based on migration matrices built from a historical database of behavioural scores. Although it is possible to calibrate score to long run probability of default if one has data over a sufficiently long outcome period that data is not available in practice. The transition matrix approach allows one to undertake such calibration using much shorter data series. In our case study we use the lenders' behavioural scores but we can use the same methodology on generic bureau scores.

The approach also helps lenders take long term lending decisions by estimating the risk associated with the change in the quality of portfolio of loans over time. Since the model includes economic conditions, the approach allows banks to stress test their retail portfolios as required by the Basel Accord and other banking regulations. In addition, the model provides insights on portfolio profitability, the determination of appropriate capital reserves, and creating estimates of portfolio value by generating portfolio level credit loss distributions.

There have been some recent papers which look at modelling the credit risk in consumer loan portfolios. Rosch and Scheule (2004) take a variant of the one factor Credit Metrics model, which is the basis of the Basel Accord. They use empirical correlations between different consumer loan types and try to build in economic variables to explain the differences during different parts of the business cycle. Perli and Nayda (2004) also take the corporate credit risk structural models and seek to apply it to consumer lending assuming that a consumer defaults if his assets are lower than a specified threshold. However consumer defaults are usually more about cash flow problems, financial naiveté or fraud and so such a model misses some of the aspects of consumer defaults. 
Musto and Souleles (2005) use equity pricing as an analogy for changes in the value of consumer loan portfolios. They use behavioural scores but take the monthly differences in behavioural scores as the return on assets when applying their equity model. Andrade and Thomas ( 2007) describe a structural model for the credit risk of consumer loans where the behavioural score is a surrogate for the creditworthiness of the borrower. A default occurs if the value of this reputation for creditworthiness, in terms of access to further credit drops below the cost of servicing the debt. Using a case study based on Brazilian credit bureau they found that a random walk was the best model for the idiosyncratic part of creditworthiness. Malik and Thomas (2010) developed a hazard model of time to default for consumer loans where the risk factors were the behavioural score, the age of the loan and economic variables, and used it to develop a credit risk model for portfolios of consumer loans. Bellotti and Crook ( 2009) also used proportional hazards to develop a default risk model for consumer loans. They investigated which economic variables, might be the most appropriate though they did not use behavioural scores in their model. Thomas $(2009 \mathrm{~b})$ reviewed the consumer credit risk models and pointed out the analogies with some of the established corporate credit risk models.

Since the seminal paper by Jarrow, Lando and Turnbull ( Jarrow et al 1997), the Markov chain approach has proved popular in modelling the dynamics of the credit risk in corporate portfolios. The idea is to describe the dynamics of the risk in terms of the transition probabilities between the different grades the rating agencies' award to the firm's bonds. There are papers which look at how economic conditions as well as the industry sector of the firm affects the transitions matrices, ( Nickell et al 2001) while others generalise the original Jarrow, Lando Turnbull idea by using Affine Markov chains 
(Hurd and Kuznetsov 2006) or continuous time processes ( Lando and Skodeberg 2002). However none of these suggest increasing the order of the Markov chain or considering the age of the loan which are two of the features which we introduce in order to model consumer credit risk using Markov chains. This is surprising because there is work on downgrading by rating agencies, which suggests there is a momentum effect in which when a company has been downgraded it is more likely to be further downgraded than to be subsequently upgraded ( Bangia et al 2002).

Markov chain models have been used in the consumer lending context before, but none of the published papers use the behavioural score as the state space nor is the objective of the models to estimate the credit risk at the portfolio level. The first application was by Cyert (1962) who developed a Markov chain model of customer's repayment behaviour. Subsequently more complex models have been developed by Ho (2001), Thomas et al (2001) and Trench et al (2003). Schneiderjans and Lock (1994) used Markov chain models to model the marketing aspects of customer relationship management in the banking environment.

Behavioural score based Markov chain models are sometimes used in the industry, see Scallan (1998) but mainly as ways of assessing provisioning estimates and they do not include the economic drivers and months on books effects presented in this paper. Moreover the introduction of economic factors into the model allows one to deal with the correlations between defaults on individual loans in a portfolio since they are affected by common economics. One can get the mean default rate in a portfolio from the long run distributions while a Monte Carlo simulation using the transitions of individual loans would give the distribution of the default rate. 
In section two, we review the properties of behavioural scores and Markov chains, while in section three we describe the Markov chain behavioural score based consumer credit risk model developed. This is parameterised by using cumulative logistic regression to estimate the transition probabilities of the Markov chain. The motivation behind the model and the accuracy of the model's forecasts are given by means of a case study and section four describes the details of the data used in the case study. Sections five, six and seven give the reasons why one includes in the model higher order transition matrices (section five); economic variables to explain the non stationarity of the chain (section six) and the age of the loan (section seven). Section eight describes the full model used, while section nine reports the results of out of sample and out of time and out of sample forecasts using the model. The final section draws some conclusions including how the model could be used. It also identifies one issue - which economic variables drive consumer credit risk - where further investigation would benefit all models of consumer credit risk.

\section{Behaviour Score Dynamics and Markov Chain models}

Consumer lenders use behavioural scores updated every month to assess the credit risk of individual borrowers. The score is considered to be a sufficient statistic of the probability a borrower will be "Bad" and so default within a certain time horizon (normally taken to be the next twelve months). Borrowers who are not Bad are classified as "Good". So at time $t$, a typical borrower with characteristics $x(t)$ ( which may describe recent repayment and usage performance, the current information available at a credit bureau on the borrower, and socio-demographic details) has a score $\mathrm{s}(\mathrm{x}(\mathrm{t}), \mathrm{t})$ so 


$$
p(B \mid x(t), t)=p(B \mid s(x(t), t))
$$

Some lenders obtain a Probability of Default (PD), required under the Basel Accord by taking a combination of behavioural and application scores. New borrowers are scored using only the application score to estimate PD: once there is sufficient history for a behavioural score to be calculated, then a weighted combination of the two scores is used to calculate PD; eventually the loan is sufficiently mature that only the behavioural score is used to calculate PD. The models described hereafter can also be applied to such a combined scoring system.

Most scores are log odds score (Thomas 2009a) so the direct relationship between the score and the probability of being Bad is given by

$s(x(t), t)=\log \left(\frac{P(G \mid s(x(t), t)}{P(B \mid s(x(t), t)}\right) \Leftrightarrow P(B \mid s(x(t), t))=\frac{1}{1+e^{s(x(t), t)}}$

though in reality this may not hold exactly. Applying Bayes theorem to (2) gives the expansion where if $\mathrm{p}_{\mathrm{G}}(\mathrm{t})$ is the proportion of the population who are Good at time $t\left(\mathrm{p}_{\mathrm{B}}(\mathrm{t})\right.$ is the proportion who are $\mathrm{Bad}$ ) one has

$$
s(x(t), t)=\log \left(\frac{P(G \mid s(x(t), t)}{P(B \mid s(x(t), t)}\right)=\log \left(\frac{p_{G}(t)}{p_{B}(t)}\right)+\log \left(\frac{P(s(x(t), t) \mid G, t)}{P(s(x(t), t) \mid B, t)}\right)=s_{p o p}(t)+w_{o} e_{t}(s(x(t), t))
$$

The first term is the log of the population odds at time $t$ and the second term is the weight of evidence for that score, (Thomas 2009a). This decomposition may not hold exactly in practice and is likely to change as a scorecard ages However it shows that the term $\mathrm{s}_{\mathrm{pop}}(\mathrm{t})$, common to the scores of all borrowers, can be thought to play the role of a systemic factor which affects the default risk of all the borrowers in a portfolio. Normally though the time dependence of a behavioural score is ignored by lenders. Lenders are usually only interested in ranking borrowers in terms of risk and they believe that the second term 
( the weight of evidence ) in (3), which is the only one that affects the ranking, is more stable over time than $\mathrm{s}_{\mathrm{pop}}(\mathrm{t})$ particularly over horizons of two or three years. However the time dependence is important because it describes the dynamics of the credit risk of the borrower. Given the strong analogies between behavioural scores in consumer credit and the credit ratings used for corporate credit risk, one obvious way of describing the dynamics of behavioural scores is to use a Markov chain approach similar to the reduced form mark to market models of corporate credit risk (Jarrow et al 1997). To use a Markov chain approach to behavioural scores, we divide the score range into a number of intervals each of which represents a state of the Markov chain, and hereafter when we mention behavioural scores we are thinking of this Markov chain version of the score, where states are intervals of the original score range.

Markov chains have proved ubiquitous models of stochastic processes because their simplicity belies their power to model a variety of situations. Formally, we define a discrete time $\left\{t_{0}, t_{1}, \ldots, t_{n}, \ldots: \mathrm{n} \in \mathrm{N}\right\}$ and a finite state space $S=\{1,2, \ldots, S\}$ first order Markov chain as a stochastic process $\left\{\mathrm{X}\left(\mathrm{t}_{\mathrm{n}}\right)\right\}_{\mathrm{n} \in \mathrm{N}}$ with the property that for any $\mathrm{s}_{0}$, $\mathrm{s}_{1}, \ldots, \mathrm{s}_{\mathrm{n}-1}, i, j \in \mathrm{S}$

$P\left[X\left(t_{n+1}\right)=j \mid X\left(t_{0}\right)=s_{0}, X\left(t_{1}\right)=s_{1}, \ldots, X\left(t_{n-1}\right)=s_{n-1}, X\left(t_{n}\right)=i\right]$

$=P\left[X\left(t_{n+1}\right)=j \mid X\left(t_{n}\right)=i\right]=p_{i j}\left(t_{n}, t_{n+1}\right)$

where $\mathrm{p}_{i j}\left(\mathrm{t}_{\mathrm{n}}, \mathrm{t}_{\mathrm{n}+1}\right)$ denotes the transition probability of going from state $i$ at time $\mathrm{t}_{\mathrm{n}}$ to state $j$ at time $t_{n+1}$. The $s \times s$ matrix of elements $\mathrm{p}_{i j}(.,$.$) , denoted \mathrm{P}\left(\mathrm{t}_{\mathrm{n}}, \mathrm{t}_{\mathrm{n}+1}\right)$, is called the first order transition probability matrix associated with the stochastic process $\left\{\mathrm{X}\left(\mathrm{t}_{\mathrm{n}}\right)\right\}_{\mathrm{n} \in \mathrm{N}}$. If $\pi\left(t_{n}\right)=\left(\pi_{1}\left(t_{n}\right), \ldots, \pi_{s}\left(t_{n}\right)\right)$ describes the probability distribution of the states of the process at time $t_{n}$, the Markov property implies that the distribution at time $t_{n+1}$ can be 
obtained from that at time $\mathrm{t}_{\mathrm{u}}$ by $\pi\left(t_{n+1}\right)=\pi\left(t_{n}\right) P\left(t_{n}, t_{n+1}\right)$. This extends to a $\mathrm{m}$-stage transition matrix so that the distribution at time $t_{n+m}$ for $m \geq 2$ is given by

$$
\pi\left(t_{n+m}\right)=\pi\left(t_{n}\right) P\left(t_{n}, t_{n+1}\right) \ldots P\left(t_{n+m-1}, t_{n+m}\right)
$$

The Markov chain is called time homogeneous or stationary provided

$$
p_{i j}\left(t_{n}, t_{n+1}\right)=p_{i j} \forall n \in N \text {. }
$$

Assume the process $\left\{\mathrm{X}\left(\mathrm{t}_{\mathrm{n}}\right)\right\}_{\mathrm{n} \in \mathrm{N}}$ is a nonstationary Markov chain, which is the case with the data we examine later. If one has a sample of histories of previous customers, let $n_{i}$ $\left(\mathrm{t}_{\mathrm{n}}\right), i \in \mathrm{S}$, be the number who are in state $i$ at time $t_{n}$, whereas let $n_{i j}\left(\mathrm{t}_{\mathrm{n}}, t_{n+1}\right)$ be the number who move from state $i$ at time $t_{n}$ to state $j$ at time $\mathrm{t}_{\mathrm{n}+1}$. The maximum likelihood estimator of $p_{i j}\left(t_{n}, t_{n+1}\right)$ is then

$$
\hat{p}_{i j}\left(t_{n}, t_{n+1}\right)=\frac{n_{i j}\left(t_{n}, t_{n+1}\right)}{n_{i}\left(t_{n}\right)} .
$$

If one assumed that the Markov chain was stationary, then given the data for $\mathrm{T}+1$ time periods $n=0,1,2, \ldots, T$, the Transition probability estimates become

$$
\hat{p}_{i j}=\frac{\sum_{n=0}^{T-1} n_{i j}\left(t_{n}, t_{n+1}\right)}{\sum_{n=0}^{T-1} n_{i}\left(t_{n}\right)}
$$

Note that the Markov property means that previous transitions do not affect the current probabilities of transition and so in these calculations we do not need to be concerned that transitions coming from the same customer are dependent. All transitions are essentially independent even those from the same customer. One can weaken the Markov property so that the information required to estimate the future of the chain is the current state and the previous state of the process. This is called a second order Markov chain which is 
equivalent to the process being a first order Markov chain but with state space $S \times S$. The concept can be generalized to defining $k^{\text {th }}$ order Markov chains for any $k$, though of course, the state space and the size of the transition probability matrices goes up exponentially as $k$ increases.

\section{Behavioural score based Markov Chain model of Consumer Credit Risk}

The behavioural score $\mathrm{B}_{\mathrm{t}}$ of a borrower is an observable variable given by a scorecard. It is related to the underlying unobservable "credit worthiness", $\mathrm{U}_{t}$ of the borrower, which also depends on the length of time the loan has been running and the current economic situation. Our model is constructed by assuming that the borrower's behavioural score is in one of a finite number of states, namely $\left\{s_{0}=D, s_{1, \ldots} s_{n}, C\right\}$ where $s_{i} i>0$ describes an interval in the behavioural score range; $\mathrm{s}_{0}=\mathrm{D}$ means the borrower has defaulted and $\mathrm{C}$ is the state when the borrower closed his loan or credit card account having repaid everything ( an absorbing state). The Markov property means that the dynamics from time t onwards of the behavioural score is conditional on the realization of the score state at time $\mathrm{t}-1, \mathrm{~B}_{\mathrm{t}-1}$ or at least that its movement between the score range intervals depends only on which current interval it is in. Given the behavioural score is in state $s_{i}, i=1, \ldots n$, at time $t-1$, we write the latent variable $\mathrm{U}_{t}$ at time $t$ as $U_{t}^{i}$. For the active accounts, $U_{t}^{i}$ is defined so that the relationship between $\mathrm{B}_{\mathrm{t}}$ and $U_{t}^{i}$ is that $B_{t}=s_{j} \Leftrightarrow \mu_{j}^{i} \leq U_{t}^{i} \leq \mu_{j+1}^{i}, \quad \mathrm{j}=0,1, . . n$ with $\mu_{0}=-\infty, \mu_{n+1}=\infty$

where $\mu_{j}^{i}$ are the values in the unobservable credit worthiness which correspond to the end points of the behavioural score intervals $s_{i}$. Moreover one chooses $\mu_{1}^{i}$ so that if the 
consumer defaults one must have $U_{t}^{i} \leq \mu_{1}^{i}$. The dynamics of the underlying variable $U_{t}^{i}$ is assumed to be related to the explanatory variable vector $x_{t-1}$ by a linear regression of the form $U_{t}^{i}=-\beta_{i}^{\prime} x_{t-1}+\varepsilon_{t}^{i}$, where $\beta_{\mathrm{i}}$ is a column vector of regression coefficients and $\varepsilon_{t}^{\mathrm{i}}$ are random error terms. If the $\varepsilon_{t}^{i}$ are standard logistic distributions, then this is a cumulative logistic regression model and the transition probabilities of $\mathrm{B}_{\mathrm{t}}$ are given by

$\operatorname{Prob}\left(\mathrm{B}_{t}=\mathrm{D}_{\mathrm{B}} \mathrm{B}_{t-1}=\mathrm{s}_{i}\right)=\operatorname{logit}\left(\mu_{1}^{i}+\beta_{i}^{\prime} x_{t-1}\right)$,

$\operatorname{Prob}\left(\mathrm{B}_{t}=\mathrm{s}_{1} \mid \mathrm{B}_{t-1}=\mathrm{s}_{i}\right)=\operatorname{logit}\left(\mu_{2}^{i}+\beta_{i}^{\prime} x_{t-1}\right)-\operatorname{logit}\left(\mu_{11}^{i}+\beta_{i}^{\prime} x_{t-1}\right)$,

$\operatorname{Prob}\left(\mathrm{B}_{t}=\mathrm{s}_{n} \mid \mathrm{B}_{t-1}=\mathrm{s}_{i}\right)=1-\operatorname{logit}\left(\mu_{n}^{i}+\beta_{i}^{\prime} x_{t-1}\right)$.

Estimating cumulative logistic model using usual maximum likelihood means that conditional on the realization the time dependent covariate vector $x_{t-1}$, transitions to various states for different borrowers in the next time period are independent both crosssectionally and through time. So the dynamics of the behavioural scores is driven by the explanatory variable $\mathrm{x}_{\mathrm{t}-1}$. In the model presented we assume three types of drivers economic variables, the age of the loan and the previous behaviour of the score. We justify these choices in sections 5 to 7 by looking at their effect on the simple first order Markov chain model. Note that states C and D are absorbing states and so there are no transitions from them and we will discuss the modeling of movements to the closed state, $\mathrm{C}$, in section 8

This has parallels with some of the corporate credit risk models. In Credit Metrics for example (Gordy 2000) the transition in corporate ratings are given by changes in the underlying "asset" variables in a similar fashion but with quite different drivers. 
Since behaviour scores are only calculated monthly, calendar time $t$ needs to be discrete and then the creditworthiness at time $t$ of a borrower, whose credit worthiness at time $t-1$ was in state $i$,is given by the latent variable $U_{t}^{i}$, which satisfies the relationship $U_{t}^{i}=-\sum_{k=2}^{K} a_{i k}$ State $_{t-k}-\mathbf{b}_{\mathbf{i}} \cdot \mathbf{E c o V a r}_{\mathbf{t}-\mathbf{1}}-c_{i} M o B_{t-1}+\varepsilon_{t}^{i}$

where State $_{t-\mathrm{k}}$ is a vector of indicator variables denoting borrower's state at time $t-k$, EcoVar $\operatorname{Var}_{t-1}$ is a vector of economic variables at time $t-1, \mathrm{MoB}_{t-1}$ is a vector of indicator variables denoting the length of time the loan has been on the books in months ( Months on Books) at time $t-1$. One could smooth this latter effect by using a continuous variable of the age of the loan but we describe the effect using more predictive binary variables for different age bands . $a, b$, and $c$ are coefficients in the expression and $\varepsilon_{t}^{i}$ is a random variable representing a logit error term. Since $U_{t}^{i}$ depends on $i$, the underlying creditworthiness at time $\mathrm{t}$ depends on the state at $\mathrm{t}-1$ and so the behavioural score at time $\mathrm{t}$ will also depend on the state, and hence the behavioural score, at time t-1. If $a_{i k} \neq 0$ then the credit worthiness at time $\mathrm{t}$ also depends on the state at time t-k and so the Markov chain model of the corresponding behavioural scores $\mathrm{B}_{\mathrm{t}}$ will be of order $\mathrm{k}$. The transitions also depend on economic variables and on the length of time the loan has been repaid. Since the coefficients depend on $i$ then the impact of these other factors will vary from state to state. If the score band intervals were of equal length and the decomposition in (3) really held then one would expect $a_{i k}=0, c_{i}=0, \mathbf{b}_{\mathbf{i}}=\mathbf{b}$ and so this model allows for more complex dynamics in the behavioural scores.

The Months on books term does not occur in any corporate credit models, but is of real importance in consumer lending ( Breeden 2007, Stepanova and Thomas 2002). Similarly 
it is rare to have higher order Markov chains models in corporate credit, though the state space is sometimes extended to include whether there have been recent upgrades or downgrades in the ratings. Thus although corporate credit models may have more complex factors affecting their dynamics such as industry type, geographical area and seniority of the debt, they are not so much affected by recent changes of state or the age of the loan which are important in consumer credit risk models.

\section{Data Description}

The dataset used for the case study in this paper contains records of credit card customers of a major UK bank who were on the books as of January 2001 together with all those who joined between January 2001 and December 2005. The data set consists of customers' monthly behavioural scores along with the information on their time since account opened, time to default or time when the account was closed within the above duration. We randomly selected approximately 50,000 borrowers for a training data set which contained their history over the period Jan 2001 - Dec 2004. We tested our Markov models using customer's performance during 2005 from a subsample of the 50,000 and also from a holdout sample of approximately 15,000 customers. Anyone, who became 90 days delinquent (even if they subsequently were cured), was charged off or declared bankrupt, is considered as having defaulted.

The bank reported that there were no major changes in credit limit setting or minimum repayment levels during the period under consideration, nor were there any changes in the scorecard or intentional attempts to change the mix of the portfolio of borrowers 
through portfolio acquisition or marketing campaigns. To analyse the changes in the distribution of behavioural score we first coarse classify behavioural score into various segments. Initially, we segment the behavioural score into deciles of the distribution of the score among all the borrowers in the sample over all the months in the sample. We use the chi-square statistic to decide whether to combine adjacent deciles if their transition probabilities are sufficiently similar. This technique of coarse classifying is standard in scorecard building (Thomas 2009a) to deal with continuous variables where the relationship with default is non linear. In this case it led to a reduction to five scorebands, namely $s_{1}=\{113-680\}, s_{2}=\{681-700\}, s_{3}=\{701-715\}, s_{4}=\{716-725\}$ and $s_{5}=\{726$ and above $\}$. As well as these five states there are two more special states corresponding to Default and Account Closed. If there are too many states in the chain the parameter estimates lose robustness, while if there are too few one loses structure and one does not have enough segments to validate the model according to the Basel Accord requirements.

Behavioural scores are generated or updated every month for each individual so it would be possible to estimate a 1-month time step transition matrix. Since transitions between some states will have very few 1 month transitions, such a model may lead to less than robust estimates of the parameters. Hence we use 3-month time steps. Longer time steps, say six or twelve months, make it harder to include the impact of the changes in economics and the months on books effect. In the following sections we shall justify the use of higher order Markov chains and provide an analysis of the effects of time varying macroeconomic and months on books covariates on behavioural score transitions. 


\section{Order of the Transition Matrix}

We first estimate the average transition matrix, assuming the Markov chain is stationary and first order using the whole duration of the sample from January 2001 to December 2004. Table 1 shows the 3-month time step transition matrix for that sample, where the figures in brackets are the standard sampling errors. As one might expect, once a borrower is in the least risky state $\left(\mathrm{s}_{5}\right)$ there is a high probability, $88 \%$, they will stay there in the next quarter. More surprisingly the state with the next highest probability of the borrower staying there is $s_{1}$, the riskiest behavioural score state, while borrowers in the other states move around more. The probabilities of defaulting in the next quarter are monotone with, as one would expect, 13-680 being the most risky state with a default probability of $6.7 \%$ and 726 -high the least risky state with a default probability of $0.2 \%$. Note that there is the obvious stochastic dominance $\left(\sum_{j \geq k} p_{i j} \leq \sum_{j \geq k} p_{i+1 j}\right)$ for all the active states, which shows that the behavioural score correctly reflects future score changes as well as future defaults.

Table 1: First Order Average Transition Matrix

\begin{tabular}{|c|c|c|c|c|c|c|c|}
\hline \multirow[t]{2}{*}{ Initial State } & \multicolumn{7}{|c|}{ Transition State } \\
\hline & $13-680$ & $681-700$ & $701-715$ & $716-725$ & 726-high & Closed & Default \\
\hline $13-680$ & $\begin{array}{l}49.0 \\
(0.2)\end{array}$ & $\begin{array}{l}22.1 \\
(0.2)\end{array}$ & $\begin{array}{c}9.6 \\
(0.1)\end{array}$ & $\begin{array}{c}4.0 \\
(0.1)\end{array}$ & $\begin{array}{c}4.0 \\
(0.1)\end{array}$ & $\begin{array}{c}4.7 \\
(0.1)\end{array}$ & $\begin{array}{c}6.7 \\
(0.1)\end{array}$ \\
\hline $681-700$ & $\begin{array}{l}15.7 \\
(0.1)\end{array}$ & $\begin{array}{l}34.7 \\
(0.2)\end{array}$ & $\begin{array}{l}25.1 \\
(0.2)\end{array}$ & $\begin{array}{c}9.6 \\
(0.1)\end{array}$ & $\begin{array}{l}11.2 \\
(0.1)\end{array}$ & $\begin{array}{c}2.8 \\
(0.1)\end{array}$ & $\begin{array}{c}0.8 \\
(0.0)\end{array}$ \\
\hline $701-715$ & $\begin{array}{c}6.0 \\
(0.1)\end{array}$ & $\begin{array}{l}13.6 \\
(0.1)\end{array}$ & $\begin{array}{l}35.9 \\
(0.2)\end{array}$ & $\begin{array}{l}18.1 \\
(0.1)\end{array}$ & $\begin{array}{l}23.4 \\
(0.1)\end{array}$ & $\begin{array}{c}2.6 \\
(0.1)\end{array}$ & $\begin{array}{c}0.5 \\
(0.0)\end{array}$ \\
\hline $716-725$ & $\begin{array}{c}3.0 \\
(0.1)\end{array}$ & $\begin{array}{l}6.1 \\
(0.1)\end{array}$ & $\begin{array}{l}15.7 \\
(0.1)\end{array}$ & $\begin{array}{l}28.3 \\
(0.2)\end{array}$ & $\begin{array}{l}44.1 \\
(0.2)\end{array}$ & $\begin{array}{c}2.5 \\
(0.1)\end{array}$ & $\begin{array}{c}0.3 \\
(0.0)\end{array}$ \\
\hline 726-high & $\begin{array}{l}0.7 \\
(0.0)\end{array}$ & $\begin{array}{c}1.2 \\
(0.0)\end{array}$ & $\begin{array}{c}2.7 \\
(0.0)\end{array}$ & $\begin{array}{c}4.3 \\
(0.0)\end{array}$ & $\begin{array}{l}88.4 \\
(0.0)\end{array}$ & $\begin{array}{c}2.4 \\
(0.0)\end{array}$ & $\begin{array}{c}0.2 \\
(0.0)\end{array}$ \\
\hline
\end{tabular}

This first order Markov chain model assumes that the current state has all the information needed to estimate the probability of the transitions next quarter and so these are unaffected by the borrower's previous states. If this is not true, one should use a second or higher order Markov chain model. This might seem surprising in that a behavioural 
score is considered to be a sufficient statistic of the credit risk. However this is a very specific credit risk - the chance of default in the next 12 months whereas the Markov chain describes the dynamics of the credit risk estimates over a different 12 month interval each period. Thus it is quite possible the score does not include all the information needed to estimate how this risk is likely to change. Table 2 displays the estimates of the transition matrix for such a second order chain, obtained in a similar way as Table 1. Analysing Table 2 shows that there are substantial changes in the transition probabilities based on the previous state of the borrower. Consider for example if the current state is the risky one $s_{1}=\{13-680\}$. If borrowers were also in the risky state last quarter then the chance of staying on it or defaulting in the next quarter is $58 \%$ $+7 \%=65 \%$; if they were in the least risky state in the last quarter $\{726+\}$ but are now in $\mathrm{s}_{1}$, the chance of being in $\mathrm{s}_{1}$ or default next quarter is $22.8 \%+7.7 \%=30.5 \%$.

Table 2: Second Order Average Transition Matrix

\begin{tabular}{|c|c|c|c|c|c|c|c|}
\hline \multirow[t]{2}{*}{ (Previous State, Current State) } & \multicolumn{7}{|c|}{ Terminal State } \\
\hline & $13-680$ & $681-700$ & $701-715$ & $716-725$ & 726-high & Closed & Default \\
\hline$(13-680,13-680)$ & 58.0 & 19.2 & 6.9 & 2.3 & 1.6 & 5.0 & 7.0 \\
\hline$(681-700,13-680)$ & 42.2 & 27.8 & 12.2 & 4.2 & 3.2 & 3.8 & 6.6 \\
\hline$(701-715,13-680)$ & 36.7 & 28.3 & 13.0 & 6.5 & 5.2 & 4.2 & 6.1 \\
\hline$(716-725,13-680)$ & 34.7 & 23.8 & 15.4 & 8.4 & 7.0 & 3.8 & 6.9 \\
\hline (726-high,13-680) & 22.8 & 18.9 & 16.0 & 9.5 & 19.9 & 5.2 & 7.7 \\
\hline$(13-680,681-700)$ & 24.5 & 36.7 & 21.3 & 7.0 & 6.6 & 3.1 & 0.8 \\
\hline$(681-700,681-700)$ & 14.0 & 40.4 & 25.7 & 8.2 & 7.9 & 3.1 & 0.7 \\
\hline$(701-715,681-700)$ & 12.4 & 34.4 & 29.4 & 10.1 & 10.3 & 2.7 & 0.7 \\
\hline$(716-725,681-700)$ & 13.8 & 27.7 & 26.8 & 12.9 & 15.5 & 2.5 & 0.8 \\
\hline (726-high,681-700) & 9.3 & 20.9 & 23.0 & 15.0 & 28.5 & 2.4 & 1.0 \\
\hline$(13-680,701-715)$ & 14.2 & 19.0 & 28.2 & 17.6 & 17.0 & 3.6 & 0.5 \\
\hline$(681-700,701-715)$ & 7.6 & 19.8 & 36.6 & 15.8 & 17.1 & 2.5 & 0.6 \\
\hline$(701-715,701-715)$ & 4.7 & 12.2 & 45.7 & 17.7 & 16.7 & 2.6 & 0.4 \\
\hline$(716-725,701-715)$ & 4.2 & 11.0 & 36.6 & 22.5 & 22.6 & 2.6 & 0.5 \\
\hline (726-high,701-715) & 4.3 & 8.9 & 24.1 & 18.3 & 41.3 & 2.6 & 0.6 \\
\hline$(13-680,716-725)$ & 9.9 & 11.8 & 16.7 & 20.9 & 37.1 & 3.2 & 0.6 \\
\hline$(681-700,716-725)$ & 4.9 & 11.3 & 19.8 & 22.6 & 37.7 & 3.4 & 0.2 \\
\hline$(701-715,716-725)$ & 3.0 & 7.5 & 21.6 & 28.9 & 36.0 & 2.7 & 0.3 \\
\hline$(716-725,716-725)$ & 2.4 & 4.5 & 15.5 & 42.1 & 32.9 & 2.4 & 0.3 \\
\hline (726-high,716-725) & 1.8 & 4.1 & 12.3 & 23.6 & 55.4 & 2.5 & 0.3 \\
\hline (13-680,726-high) & 5.5 & 5.6 & 7.9 & 8.5 & 69.3 & 3.1 & 0.2 \\
\hline (681-700,726-high) & 3.1 & 6.4 & 10.2 & 12.1 & 64.7 & 3.2 & 0.3 \\
\hline (701-715,726-high) & 2.1 & 4.1 & 9.6 & 12.2 & 68.8 & 2.9 & 0.3 \\
\hline (716-725,726-high) & 1.5 & 3.0 & 6.6 & 12.1 & 73.8 & 2.8 & 0.2 \\
\hline (726-high,726-high) & 0.5 & 0.8 & 2.0 & 3.4 & 90.7 & 2.4 & 0.2 \\
\hline
\end{tabular}


So there is a propensity to reverse direction and return in the direction one came. This effect is seen in all the five behavioural score interval states in the model. These results do not support the "momentum" idea that borrowers whose score has dropped are more likely to drop further (see Bangia et al 2002 for examples in corporate credit), but suggests there may be some event of very short duration which appears and then is reversed in the next quarter, such as being put in arrears due to some misunderstanding. This effect seen in all five states could be due to using score bands rather than the scores themselves and so the previous score band might suggest where in the interval the score is. However the same result was seen when a finer classification, i.e. more states with smaller intervals, was used. One could investigate whether higher order models are even more appropriate but for third and higher order Markov chains data sparsity and robustness of predictions become problems and so we use a second order chain to model the dynamics of the behavioural scores.

\section{Macro Economic Variables}

Traditionally behavioural score models are built on customers performance with the bank over the previous twelve months using characteristics like average account balance, number of times in arrears and current credit bureau information. So the behavioural score can be considered as capturing the borrower's specific risk. However, in corporate credit risk models (Das et al, 2007), it was shown that though borrower specific risk is a major factor, during economic slowdowns systemic risk factors emerge and have had a substantial effect on the default risk in a portfolio of loans. The decomposition of the behavioural score in (3) suggests this is also the case in consumer lending, since the 
population $\log$ odds $s_{\text {pop }}(t)$ must be affected by such systemic changes in the economic environment. The question is which economic variables affect the default risk of consumers. We investigate five variables which have been suggested as important in consumer finance ( Tang et al 2007, Liu and Xu 2003), together with one variable that reflects market conditions in consumer lending. The variables considered are:

(a) Percentage Change in Consumer Price Index over 12 Months: reflects the inflation felt by customers and high levels may cause rise in customer default rate.

(b) Monthly average Sterling Inter-bank lending rate: higher values correspond to general tightness in the economy as well as increases in debt service payments.

(c) Annual Return on FTSE 100: gives the yield from stock market and reflects the buoyancy of industry.

(d) Percentage change in GDP compared with equivalent Quarter in Previous Year:

(e) UK Unemployment Rate.

(f) Percentage Change in Net Lending over 12 Months: this gives an indication of the funds being made available for consumer lending.

There is a general perception (Figlewski et al, 2007) that change in economic conditions do not have an instantaneous effect on default rate. To allow for this, we use lagged values of the macroeconomic covariates in the form of weighted average over a six months period with an exponentially declining weight of 0.88 . This choice is motivated by the recent study made by (Figlewski et al, 2007). Since macro economic variables represent the general health of the economy they are expected to show some degree of correlation. Table 3 below shows the pairwise correlation matrix for the above six 
macroeconomic variables with no lags considered. The entries in bold are the correlations considered statistically significant at the $5 \%$ level. Thus at a 5\% significance level interest rate is negatively correlated with percentage change in CPI and positively correlated with percentage change in GDP and return on the FTSE 100. Similarly, percentage change in Net Lending is negatively correlated with Unemployment rate and positively correlated with percentage change in GDP and return on the FTSE 100 at 5\% significance level. The presence of non zero correlation between variables does not invalidate the model, but the degree of association between the explanatory variables can affect parameter estimation. Moreover the variables used are chosen in so as to avoid long run trends and the fact that three of the variables are percentage changes is akin to already taking differences to avoid non stationarity

Table 3: Correlation matrix of macroeconomic factors

\begin{tabular}{|c|c|c|c|c|c|c|}
\hline & $\begin{array}{l}\text { Interest } \\
\text { Rate }\end{array}$ & $\begin{array}{l}\% \text { change in } \\
\text { CPI }\end{array}$ & $\begin{array}{l}\% \text { change in } \\
\text { GDP }\end{array}$ & $\begin{array}{l}\% \text { change in } \\
\text { net lending }\end{array}$ & $\begin{array}{l}\text { unemployment } \\
\text { rate }\end{array}$ & $\begin{array}{l}\text { Return on } \\
\text { FTSE } 100\end{array}$ \\
\hline Interest Rate & 1 & -0.51 & 0.34 & 0.14 & 0.01 & 0.39 \\
\hline$\%$ change in CPI & -0.51 & 1 & -0.11 & -0.23 & -0.45 & -0.09 \\
\hline$\%$ change in GDP & 0.34 & -0.11 & 1 & 0.85 & -0.71 & 0.87 \\
\hline$\%$ change in net lending & 0.14 & -0.23 & 0.85 & 1 & -0.49 & 0.70 \\
\hline unemployment rate & 0.01 & -0.45 & -0.71 & -0.49 & 1 & -0.73 \\
\hline Return on FTSE 100 & 0.39 & -0.09 & 0.87 & 0.70 & -0.73 & 1 \\
\hline
\end{tabular}

Figure 1 shows the variation of the observed $\log$ (Default Odds) over 3 month windows compared with the lagged macroeconomic factor values used in the analysis for the 
sample duration of January 2001 to December 2004. The macroeconomic factors values are represented by the primary y-axis and the $\log$ (Default Odds) by the secondary y-axis. Figure 1:3-Month Observed $\log ($ Odds Default) and Macroeconomic variables

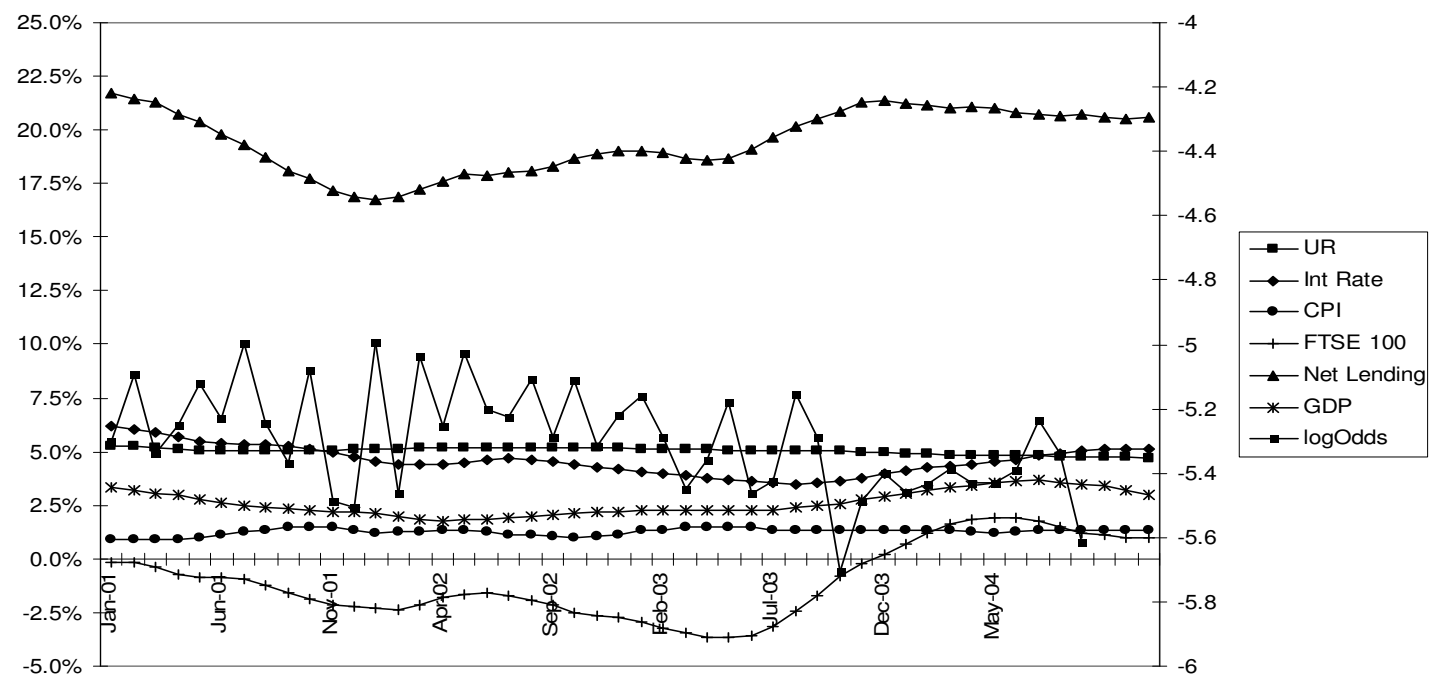

We plot the lagged economic values for each month though of course we only use the values every quarter in the Markov chain model since its time period is quarterly. In the benign environment of 2001-4 there are no large swings in any variable and the log of the default odds $-\mathrm{s}_{\mathrm{pop}}(\mathrm{t})-$ is quite stable.

To convince ourselves that changes in economic conditions do affect the transitions matrix, we look at transition matrices based on data from two different time periods, which have slightly different economic conditions. In order not to complicate matters we show the differences that occur even in the first order Markov chain. In Table 4, we estimate the first order transition probability matrices for two different twelve months calendar time periods between Jan 2001 to December 2004 to judge the effect of calendar time on transition probabilities. The first matrix is based on sample of customers who were on books during Jan-Dec 2001 and uses their transitions each quarter during that 
period and the second is based on those in the portfolio during Sept03 - Oct04 and their performance during that period. Both transition matrices show considerable similarities with the whole sample average transition matrix in Table 1, with the probability of moving into default decreasing as the behavioural score increases and the stochastic dominance effect still holding. However there are some significant differences between the transition probabilities of the two matrices in Table 4. For example, borrowers who were in current state of $s_{1}=\{13-680\}$ during Jan-Dec 2001 have a lower probability of defaulting in the next quarter $-5.5 \%$ - than those who were in the same state

Table 4: Comparison of transition matrices at different calendar times

\begin{tabular}{|c|c|c|c|c|c|c|c|c|}
\hline \multirow[t]{2}{*}{ Initial state } & \multicolumn{8}{|c|}{ Terminal State } \\
\hline & $13-680$ & $681-700$ & $701-715$ & $716-725$ & 726- & Closed & Default & number in state \\
\hline \multicolumn{9}{|c|}{ Jan-Dec 2001} \\
\hline $13-680$ & 52.90 & 21.77 & 9.24 & 3.62 & 3.67 & 3.31 & 5.50 & 24015 \\
\hline $681-700$ & 17.80 & 35.56 & 23.86 & 9.51 & 10.40 & 2.14 & 0.72 & 25235 \\
\hline $701-715$ & 8.74 & 14.84 & 35.25 & 17.90 & 22.72 & 2.16 & 0.40 & 31477 \\
\hline $716-725$ & 3.28 & 6.99 & 16.84 & 27.85 & 42.64 & 2.12 & 0.29 & 27781 \\
\hline 726- & 0.72 & 1.35 & 2.86 & 4.30 & 88.39 & 2.10 & 0.28 & 220981 \\
\hline \multicolumn{9}{|c|}{ Oct 03-Sept 04} \\
\hline $13-680$ & 46.24 & 22.68 & 9.30 & 4.03 & 4.18 & 5.35 & 8.22 & 24060 \\
\hline $681-700$ & 14.79 & 35.62 & 23.25 & 9.80 & 10.99 & 2.74 & 0.82 & 25235 \\
\hline $701-715$ & 5.42 & 13.42 & 37.30 & 18.20 & 22.89 & 2.33 & 0.43 & 42200 \\
\hline $716-725$ & 2.68 & 5.63 & 16.17 & 29.34 & 43.79 & 2.05 & 0.33 & 38932 \\
\hline 726- & 0.62 & 1.14 & 2.65 & 4.69 & 88.80 & 1.90 & 0.19 & 289814 \\
\hline
\end{tabular}


during Sept03 - Oct04 where the value is $8.22 \%$. We test the difference between the corresponding transition probabilities in the two matrices in Table 4 using the twoproportion z-test with unequal variances. The entries in bold in Table 4 identify those transition probabilities where the differences between the corresponding terms in the two matrices are significant at the 5\% level. Note that there are 35 transition probabilities being compares and so one might expect 2 significant comparions at the $5 \%$ level if there were really no difference. There are 20 significant differences which suggest this calendar effect is real.

\section{Months on Books Effects}

As is well known in consumer credit modeling (Breeden 2007, Stepanova and Thomas 2002), the age of the loan (the number of months since the account was opened) is an important factor in default risk. To investigate this we split age into seven segments namely, 0-6 months , 7-12 months, 13-18 months , 19-24 months , 25-36 months , 37-48 months , more than 48 months.. The effect of age on behavioural score transition probabilities can be seen in Table 5, which shows the first order probability transition matrices for borrowers who were on books between one to twelve months ( upper table) and more than 48 months ( lower table). Again the overall structure is similar to Table 1, but there are significant differences between the transition probabilities of the two matrices. Borrowers who are new on the books are more at risk of defaulting or of their behavioural score dropping than those who were with the bank for more than four years. The bold entries again represent transitions where the differences between the new and mature accounts are significantly different at the 5\% level.4in the Again the final block of 
Table 5 gives the $\mathrm{z}$ statistic and the bold values indicate where in the tables the differences in transitions are statistically significant at the 5\% level. This occurs in 27 out of the 35 transitions calculated

Table 5: Comparison of transition matrices for loans of different ages

\begin{tabular}{|c|c|c|c|c|c|c|c|c|}
\hline \multirow[t]{2}{*}{ Initial state } & \multicolumn{8}{|c|}{ Terminal State } \\
\hline & $13-680$ & $681-700$ & $701-715$ & $716-725$ & $726-$ & Closed & Default & number in state \\
\hline \multicolumn{9}{|c|}{$1-12$ months ( new obligors) } \\
\hline $13-680$ & 51.0 & 22.3 & 8.1 & 3.1 & 2.0 & 5.8 & 7.6 & 24858 \\
\hline $681-700$ & 18.2 & 35.6 & 24.2 & 9.3 & 8.7 & 3.2 & 0.8 & 22019 \\
\hline $701-715$ & 8.1 & 15.9 & 30.5 & $\mathbf{1 7 . 8}$ & 25.6 & 2.7 & 0.5 & 21059 \\
\hline $716-725$ & 4.5 & 8.2 & 14.7 & 21.4 & 48.6 & 2.2 & 0.3 & 18050 \\
\hline $726-$ & 1.8 & 3.0 & 5.7 & 7.6 & 79.3 & 2.3 & 0.2 & 59767 \\
\hline \multicolumn{9}{|c|}{ 49-high( mature obligors) } \\
\hline $13-680$ & 44.1 & 23.5 & 11.3 & 4.9 & 7.0 & 4.0 & 5.3 & 28604 \\
\hline $681-700$ & 13.6 & 32.5 & 25.6 & 10.7 & 14.4 & 2.5 & 0.6 & 39835 \\
\hline $701-715$ & 4.7 & 11.8 & 37.2 & 18.8 & 24.8 & 2.5 & 0.3 & 66389 \\
\hline $716-725$ & 2.1 & 5.0 & 14.9 & 30.4 & 44.7 & 2.6 & 0.3 & 67660 \\
\hline 726- & 0.4 & 0.9 & 2.1 & 3.7 & 90.4 & 2.4 & 0.2 & 698782 \\
\hline
\end{tabular}

\section{Modeling Transition Probabilities}

Behavioural score segments have a natural ordering structure with low behavioural score associated with high default risk and vice versa. This is the structure that is exploited 
when using cumulative (ordered) logistic regression to model borrowers' transitions probabilities as suggested in section 3. (McElvey and Zavoina, 1975).

The cumulative logistic regression model is appropriate for modelling the movement between the behavioural scorebands and the defaulted state. If we wished also to model whether the borrowers close their accounts one would need to use a two stage model. In the first stage, one would use logistic regression to estimate the probability of the borrower closing the account in the next quarter given his current state, $\mathrm{P}(\mathrm{Closelbeh}$.score band). The second stage would be the model presented here of the movement between the different scorebands including default conditional on the borrower not closing the account. To arrive at the final transition probabilities one would need to multiply the probabilities for each transition obtained in this second stage by the chance the account is not closed obtained from the first stage, (1-P(Closel beh.score band)). This approach assumes the residuals of the estimations in the two stages are independent.

So we now fit the cumulative logistic model to estimate the transition probabilities of a borrower's movement in behavioural score from being in state $i$ at time $\mathrm{t}-1 B_{t-1}=s_{i}$ to where the borrower will be at time $\mathrm{t}, B_{t}$. These transitions depend on the current state $B_{t-1}=s_{i}($ since they are indexed by $i)$, the previous state of the borrower, $B_{t-2}$, the lagged economic variables and the age of the loan ( Months on Books or MoB). So one uses the model given by (6) and (8) but restricted to the second order case, namely

$$
\begin{aligned}
& B_{t}=s_{j} \Leftrightarrow \mu_{j}^{i} \leq U_{t}^{i} \leq \mu_{j+1}^{i}, \quad \mathrm{j}=0,1, . . n \text { with } \mu_{0}=-\infty, \mu_{n+1}=\infty \\
& U_{t}^{i}=-a_{i} \text { State }_{t-2}-b_{i} \text { EcoVar }_{t-1}-c_{i} \text { MoB }_{t-1}+\varepsilon_{t}^{i}
\end{aligned}
$$

In order to choose which economic variables to include, we recall that Table 3 described the correlation between the variables. To reduce the effect of such correlations (so that 
the coefficients of the economic variables are understandable), we considered various subsets of the macro economic variables as predictors in a cumulative logistic model, where there was little correlation between the variables. In Table 6 we present parameter estimates for the cumulative logistic models for each behavioural score segment with only two macroeconomic variables, namely interest rate and net lending, along with months on books and the previous state. This means we allow the drivers of the dynamics - economic variables and current duration of loan- to have different effects on the transitions from different states. The model with these two variables- interest rate and net lending- provided a better fit in terms of the likelihood ratio of the model than other combinations of macroeconomic variables- the next best fit was unemployment and interest rates. We employ stepwise selection keeping only variables with a 5\% significance level for the corresponding regression coefficient to be non-zero. The likelihood ratios and the associated p-values show that for each current behavioural score segment, transitions to other states in the next time period are significantly influenced by current macroeconomic factors, current months on books and information on previous state, represented by a Secstate variable in Table 6. This model fits the data better than the first order average transition matrix. A positive sign of the coefficient in the model is associated with a decrease in creditworthiness and vice versa. So the creditworthiness of borrowers decreases in the next time period with an increase in interest rates in all current behavioural score segments.

Borrowers who are between 7 and 18 months on the books have higher default and downgrading risks than the others. This confirms the market presumption that new borrowers have higher default risk than older borrowers in any give time period, once 
they have had sufficient time (i.e at least 3 months) to default. The coefficients of the Secstate variable, with one exception, decrease monotonically in value from the $s_{1}=\{13-$ $680\}$ category to the $s_{5}=\{726$-high $\}$ state. Those with lower behavioural score last quarter are more likely to have lower behavioural score next quarter than those with the same behavioural score currently but who came from higher behavioural score bands. So the idea of credit risk continuing in the same direction is not supported.

Table 6: Parameters for second order Markov chain with age and economic variables

\begin{tabular}{|c|c|c|c|c|c|c|c|c|c|c|}
\hline \multicolumn{11}{|c|}{ ehavioural Score } \\
\hline & $13-680$ & Std Error & $681-700$ & Std Error & $701-715$ & Std Error & $716-725$ & Std Error & 726-high & Std Error \\
\hline $\begin{array}{l}\text { Interest Rate } \\
\text { Net Lending }\end{array}$ & 0.0334 & $(0.0161)$ & 0.092 & $(0.0143)$ & $\begin{array}{l}0.0764 \\
0.0129\end{array}$ & $\begin{array}{c}(0.0123) \\
(0.00489)\end{array}$ & 0.0834 & $(0.0134)$ & 0.0778 & $(0.00885)$ \\
\hline \multicolumn{11}{|l|}{ Months on Books } \\
\hline $0-6$ & -0.027 & $(0.0351)$ & 0.0161 & $(0.0347)$ & -0.2182 & $(0.0368)$ & -0.1637 & $(0.0448)$ & -0.0849 & $(0.0315)$ \\
\hline 7-12 & 0.2019 & $(0.0241)$ & 0.1247 & $(0.0225)$ & 0.2051 & $(0.0226)$ & 0.2317 & $(0.0261)$ & 0.3482 & $(0.018)$ \\
\hline $13-18$ & 0.2626 & (0.0262) & 0.2663 & $(0.0236)$ & 0.2301 & (0.0228) & 0.2703 & $(0.0268)$ & 0.2554 & $(0.0193)$ \\
\hline $19-24$ & -0.07 & $(0.0275)$ & -0.0796 & $(0.0251)$ & -0.1001 & $(0.0241)$ & -0.0873 & $(0.0284)$ & 0.031 & $(0.0206)$ \\
\hline $25-36$ & -0.0015 & $(0.0244)$ & -0.0521 & (0.0223) & 0.00191 & $(0.0198)$ & -0.00487 & $(0.0229)$ & -0.0254 & (0.0162) \\
\hline $37-48$ & -0.0703 & $(0.0262)$ & -0.0519 & $(0.0243)$ & 0.019 & $(0.0206)$ & -0.0801 & $(0.0241)$ & -0.00709 & $(0.0166)$ \\
\hline 49-high & -0.2957 & & -0.2235 & & -0.13781 & & -0.16603 & & -0.51721 & \\
\hline \multicolumn{11}{|l|}{ SecState } \\
\hline $13-680$ & 0.8372 & $(0.0165)$ & 0.6762 & $(0.0168)$ & 0.5145 & $(0.0222)$ & 0.3547 & $(0.0337)$ & 0.381 & $(0.0399)$ \\
\hline $681-700$ & 0.2365 & $(0.0201)$ & 0.2847 & $(0.0139)$ & 0.3598 & $(0.0146)$ & 0.1942 & $(0.0224)$ & 0.5168 & $(0.024)$ \\
\hline $701-715$ & -0.0111 & (0.0249) & 0.0491 & $(0.0168)$ & 0.1314 & $(0.0119)$ & 0.1255 & $(0.0164)$ & 0.2991 & $(0.0178)$ \\
\hline $716-725$ & -0.1647 & $(0.0345)$ & -0.1764 & $(0.0239)$ & -0.1795 & $(0.016)$ & 0.0098 & $(0.0152)$ & 0.0525 & $(0.0162)$ \\
\hline 726-high & -0.8979 & & -0.8336 & & -0.8262 & & -0.6842 & & -1.2494 & \\
\hline \multicolumn{11}{|l|}{ Intercept/Barrier } \\
\hline Default & -3.213 & $(0.0756)$ & -5.4389 & $(0.0826)$ & -5.8904 & (0.1285) & -6.011 & $(0.0967)$ & -5.1834 & $(0.0506)$ \\
\hline $13-680$ & -0.2078 & $(0.0734)$ & -2.179 & $(0.0657)$ & -3.2684 & $(0.1175)$ & -3.6011 & $(0.0648)$ & -3.8213 & $(0.0436)$ \\
\hline $681-700$ & 1.022 & $(0.0736)$ & -0.3978 & $(0.0649)$ & -1.9492 & $(0.1168)$ & -2.461 & $(0.062)$ & -2.9445 & $(0.0421)$ \\
\hline $701-715$ & 1.9941 & $(0.0746)$ & 0.861 & $(0.065)$ & -0.1796 & $(0.1165)$ & -1.2049 & $(0.0611)$ & -2.06 & $(0.0415)$ \\
\hline $716-725$ & 2.7666 & $(0.0764)$ & 1.6267 & $(0.0656)$ & 0.7317 & & 0.171 & $(0.0609)$ & -1.326 & $(0.0413)$ \\
\hline Likelihhod Ratio & 3661.078 & & 3379.459 & & 4137.587 & & 2838.765 & & 20400.65 & \\
\hline P-value & $<0.0001$ & & $<0.0001$ & & $<0.0001$ & & $<0.0001$ & & $<0.0001$ & \\
\hline
\end{tabular}

\section{Forecasting Multi-Period Transition Probabilities}

The model with the parameters given in Table 6 was tested by forecasting the future distributions of the scorebands in the portfolio, including those who have defaulted. The 
forecast uses the Markov assumption and so multiplies the probability transition matrix by itself the appropriate number of times to get the forecasts. In the first case we consider all non-defaulted borrowers in December 2004 and used the model to predict their distribution over the various behavioral score bands and the default state at the end of each quarter of 2005 , where closures were dealt with as described in section 8 . Not to add extra uncertainty to the forecast, the 2005 values of the two economic variables were used. The results are shown in Table 7. The initial distribution column gives the distribution of borrowers into each behavioural score segment in the test sample in December 2004. The observed column gives the observed distribution of borrowers at the end of each quarter in 2005. The other two columns gives the expected number of borrowers in each segment at the end of each quarter of 2004 as predicted by the second order average transition matrix in Table 2 and those predicted by the model in Table 6.

Table 7: Distribution at the end of each time period on out of time sample test sample (2005)

\begin{tabular}{|c|c|c|c|c|c|c|c|c|c|c|c|c|c|}
\hline \multirow{2}{*}{$\begin{array}{l}\text { Behavioural Score } \\
\text { Segments }\end{array}$} & \multicolumn{4}{|c|}{ 1-Period } & \multicolumn{3}{|c|}{ 2-Period } & \multicolumn{3}{|c|}{ 3-Period } & \multicolumn{3}{|c|}{ 4-Period } \\
\hline & \begin{tabular}{|l|} 
Initial \\
Distribution
\end{tabular} & $\begin{array}{l}\text { Average } \\
\text { Matrix }\end{array}$ & $\begin{array}{l}\text { Model } \\
\text { Predicted }\end{array}$ & Observed & $\begin{array}{l}\text { Average } \\
\text { Matrix }\end{array}$ & $\begin{array}{l}\text { Model } \\
\text { Predicted }\end{array}$ & Observed & $\begin{array}{l}\text { Average } \\
\text { Matrix }\end{array}$ & $\begin{array}{l}\text { Model } \\
\text { Predicted }\end{array}$ & Observed & \begin{tabular}{|l|} 
Average \\
Matrix
\end{tabular} & $\begin{array}{l}\text { Model } \\
\text { Predicted }\end{array}$ & Observed \\
\hline $13-680$ & 571 & 520 & 560 & 457 & 498 & 561 & 384 & 475 & 566 & 424 & 457 & 573 & 368 \\
\hline $681-700$ & 659 & 659 & 696 & 595 & 635 & 702 & 594 & 612 & 711 & 604 & 592 & 719 & 592 \\
\hline $701-715$ & 1094 & 1011 & 1066 & 982 & 969 & 1065 & 918 & 935 & 1073 & 1007 & 908 & 1081 & 938 \\
\hline $716-725$ & 973 & 936 & 1027 & 952 & 902 & 1036 & 1038 & 878 & 1044 & 971 & 859 & 1049 & 943 \\
\hline 726-high & 7436 & 7535 & 7304 & 7666 & 7589 & 7208 & 7644 & 7627 & 7098 & 7511 & 7647 & 6989 & 7612 \\
\hline Default & 0 & 72 & 80 & 81 & 140 & 160 & 155 & 206 & 241 & 216 & 270 & 322 & 280 \\
\hline
\end{tabular}

The second order Markov chain model with economic variables gave predictions, particularly for defaults, which were very close to the actual values for the first and second quarters, but begin to overestimate the risks thereafter. So by the fourth quarter the average second order Markov chain model which just takes the average of the transition probabilities is superior.

The analysis was repeated on an out of time and out of sample portfolio. Again the distribution of the portfolio at the start of the period (April 2005) was given and estimates 
for the next three quarters obtained using the model in Table 6 . The results in Table 8 show that the second order model with economic and months on books effect (Table 6) is better at predicting the actual number of defaults than the second order model without these effects (Table 3) even though both approaches slightly under predict. The model with the extra drivers is better at predicting the numbers in the default and high risk states, while the second order one that just averages over all transitions is better at predicting the numbers in the low risk categories. In this data set it appears the second order effect is the most important followed by the Months on books effect. However this could be due to the relative economic stability throughout both the period represented by both the development sample and the out of time test sample.

Table 8 Distribution at the end of each time period on out of time out of sample test sample (2005)

\begin{tabular}{|c|c|c|c|c|c|c|c|c|c|c|}
\hline \multirow{2}{*}{$\begin{array}{c}\text { Behavioural Score } \\
\text { Segments }\end{array}$} & \multicolumn{4}{|c|}{ 1-Period } & \multicolumn{3}{|c|}{ 2-Period } & \multicolumn{3}{|c|}{ 3-Period } \\
\hline & $\begin{array}{l}\text { Initial } \\
\text { Distribution }\end{array}$ & $\begin{array}{l}\text { Average } \\
\text { Matrix }\end{array}$ & $\begin{array}{l}\text { Model } \\
\text { Predicted }\end{array}$ & Observed & \begin{tabular}{|l} 
Average \\
Matrix
\end{tabular} & $\begin{array}{l}\text { Model } \\
\text { Predicted }\end{array}$ & Observed & \begin{tabular}{|l} 
Average \\
Matrix
\end{tabular} & $\begin{array}{l}\text { Model } \\
\text { Predicted }\end{array}$ & Observed \\
\hline $13-680$ & 1428 & 949 & 1040 & 1199 & 879 & 983 & 1080 & 769 & 889 & 1043 \\
\hline $681-700$ & 1278 & 1054 & 1117 & 1096 & 978 & 1061 & 1076 & 894 & 996 & 1001 \\
\hline $701-715$ & 1379 & 1291 & 1384 & 1257 & 1262 & 1393 & 1316 & 1216 & 1363 & 1219 \\
\hline $716-725$ & 876 & 1047 & 1178 & 812 & 1051 & 1228 & 774 & 1044 & 1234 & 718 \\
\hline 726-high & 7514 & 7994 & 7621 & 7968 & 8059 & 7535 & 7943 & 8208 & 7596 & 8074 \\
\hline Default & 0 & 139 & 134 & 143 & 245 & 274 & 286 & 344 & 397 & 420 \\
\hline
\end{tabular}

\section{Conclusions}

The paper has developed a pilot scheme on how one could use a Markov chain approach based on behavioural scores to estimate the credit risk of portfolios of consumer loans. This is an attractive approach since behavioural scores are calculated monthly by almost all lenders in consumer finance, both for internal decision purposes and for Basel Accord requirements. The paper emphasises that behavioural scores are dynamic and since they do have a "systemic" factor - the population odds part of the score- the dynamics depends on changes in economic conditions. The paper also suggests one needs to 
consider carefully the appropriate order of the Markov chain. Table 2 shows the impact of the previous state as well as the current state on the subsequent transition and strongly suggests the need for a second order Markov chain.

Unlike corporate credit risk, one also needs to include the age of the loan into the modelling as this affects the credit risk. The out of sample comparison of second order models with and without economic factors and age in the model are inconclusive about which model is better but this is a time when the economic conditions were very stable. In more volatile conditions or if one wants to use the model for stress testing then it will be essential to include the economic effects into the modelling.

Such models are relatively easy for banks to develop since they have all the information readily available. The model would be useful for a number of purposes - debt provisioning estimation, stress testing in the Basel context as well as investigating the relationship between Point in Time Behaviour Scores and through the cycle probabilities of default by running the model through an economic cycle. The model could also be used by ratings agencies to update their risk estimates of the securitized products based on consumer loan portfolios. This would require then to obtain regular updates of the behavioural scores of the underlying loans rather than the present approach of just making one initial rating based on an application or bureau score. This is extra work but might avoid the failures of the rating of the mortgage backed securities (MBS) seen in 2007 and 2008 and would certainly give early warning of the increasing credit risk in such securities. 
There are still issues to be resolved in modelling the credit risk of consumer loan portfolios. One important one is to identify what economic variables most affect consumer credit risk and hence should be included on such models. One would expect some differences with those which have been recognised in corporate credit risk modelling, and one may want to use different variables for different types of consumer lending. House price movements will be important for mortgages but may be less important for credit cards. One also feels that some of the variables in the models should reflect the market conditions as well as the economic conditions, because the tightening in consumer lending which prevented customers refinancing did exacerbate the problems of 2007 and 2008. This paper has described how such information on economic and market conditions can be used in conjunction with behavioural scores to estimate portfolio level consumer credit risks. It points out that though Markov chain models based on behavioural scores have been used by the industry this has not appeared previously in the literature and certainly there has been no extension of the model to include the maturity of the loan, the economic factors and the need for higher order Markov chains.

\section{Acknowledgements}

We are grateful to the EPSRC for providing funding under the Quantitative Financial Risk Management Centre to support MM. We are also grateful to two referees for their careful reading and helpful suggestions concerning the paper.

\section{References}

Andrade F.W.M., Thomas L.C., ( 2007), Structural models in consumer credit, European Journal of Operational Research 183, 1569-1581. 
Bangia A., Diebold F., Schuermann T., (2002), Ratings migration and the business cycle with applications to credit portfolio stress testing, J. Banking and Finance 24, 445-472. Basel Committee on Banking Supervision (2005, comprehensive version 2006), International convergence of capital measurement and capital standards - a revised framework, Bank for International Settlements, Basel

Bellotti T. and Crook, J.N..(2009) Credit scoring with macroeconomic variables using survival analysis. Journal of the Operational Research Society, 60, 1699-1707.

Breeden J.L., (2007), Modeling data with multiple time dimensions, Computational Statistics and Data Analysis 51, 4761-4785.

Crouhy M, Galai D., Mark R, ( 2001), Risk Management, McGraw Hill, New York Cyert R.M., Davidson H.J., Thompson G.L., (1962), Estimation of allowance for doubtful accounts by Markov Chains, Management Science 8, 287-303.

Das, S R., Duffie D., Kapadia N., Saita, L. (2007) Common Failings: How Corporate Defaults are Correlated. Journal of Finance 62, 93-117.

Demyanyk Y.S.and van Hemert O., (2008), Understanding the subprime mortgage crisis, Working Paper, Federal Reserve Bank of Cleveland and New York University .URL: http://papers.ssrn.com/sol3/papers.cfm?abstract_id=1020396.

Figlewski S, Frydman H., Liang W (2007). Modelling the Effect of Macroeconomic Factors on Corporate Default and Credit Rating Transitions. Working Paper No. FIN-06007, NYU Stern School of Business.

Gordy M (2000), A Comparative Anatomy of Credit Risk Models, Journal of Banking and Finance 24, 119-149. 
Ho J., (2001), Modelling bank Customers Behaviour using Data Warehouses and Incorporating Economic indicators, Ph.D. thesis, University of Edinburgh, Edinburgh. Hull J.C., (2009), The credit crunch of 2007: what went wrong?Why? What lessons can be learnt?, Journal of Credit Risk, 5, Number 2, 3-18.

Hurd T.R. and Kuznetsov, (2006), Affine Markov chain model of multiform credit migration, Journal of Credit Risk 3, 3-29

Jarrow R.A., Lando D. Turnbull S., (1997). A Markov model for the term structure of credit risk spreads, Review of Financial Studies, 19, 481-523

Lando D. and Skodeberg T, (2002), Analyzing rating transitions and rating drift with continuous observations, Journal of Banking and Finance 26, 423-444

Liu J. and Xu X.E., (2003), The predictive power of economic indicators in consumer credit risk management, RMA Journal, September McElvey, R.D. and Zavoina, W., (1975). A statistical model for the analysis of ordinal level dependent variables. Journal of Mathematical Sociology 4, pp. 103-120. Malik M. and Thomas L.C.,(2010), Modelling the credit risk of portfolios of consumer loans , Journal of the Operational Research Society , 61, 411-420 Musto D.K. and Souleles N., (2005), A portfolio view of consumer credit, Working Paper 05-25, Federal Reserve Bank of Philadelphia, Philadelphia.

Nickell P., Perraudin W., Varoli S.,(2001), Stability of ratings transitions, Journal of Banking and Finance 24, 203-227.

Perli R.and Nayda W.I.,(2004) Economic and Regulatory Capital Allocation for revolving retail exposures. Journal of Banking and Finance, 28, 789-809). 
Rosch D. and Scheule H, (2004), Forecasting retail portfolio credit risk, Journal of Risk Finance, 5, Volume 2, 16-32

Scallan G., (1998), Bad Debt Projection Models, An Overview of Modelling approaches, http://www.scoreplus.com/docs/BadDebt.pdf

Schniederjans M.J.and Loch K.D., (1994), An aid for strategic marketing in the banking industry: a Markov analysis, Computers and Operations Research 21, 281-287.

Stepanova M and Thomas L C (2002). Survival Analysis Methods for Personal Loan Data. Operations Research. 50, 277-289.

Tang L, Thomas L C, Thomas S and Bozzetto J-F (2007). It's the economy stupid: Modelling financial product purchases, International Journal of Bank Marketing, 25, 22-38. Trench M.S., Pederson S.P., Lau E.T., Lizhi M., Hui W., Nair S.K., (2003), Managing Credit Lines for bank One credit cards, Interfaces 33, Issue 5, 4-22.

Thomas L.C., Ho J., Scherer W.T.,(2001) Time will tell: Behavioural scoring and the dynamics of consumer risk assessment, IMA J. of Management Mathematics, 12, 89-103. Thomas L.C., (2009a) Consumer Credit Models: Pricing, Profit and Portfolios, Oxford University Press, Oxford.

Thomas L.C, ( 2009b): Modelling the Credit Risk for Portfolios of Consumer Loans: Analogies with corporate loan models, Mathematics and Computers in Simulation 20, $2525-2534$ 